\title{
CURRÍCULOS DE CURSOS TÉCNICOS \\ SUBSEQUENTES/CONCOMITANTES DO IFSUDESTE-MG: FORMAÇÃO PARA O MERCADO OU PARA O MUNDO DO TRABALHO?
}

\author{
Anelisa de Castro Quintão ${ }^{1}$ \\ Ataualpa Luiz de Oliveira ${ }^{2}$ \\ DOI: https://doi.org/10.36524/profept.v5i2.844
}

\section{RESUMO}

O presente artigo analisa currículos de cursos subsequentes/concomitantes do IFSUDESTEMG/Campus Juiz de Fora, identificando elementos que indicam concepções de Educação Profissional referenciadas para o mundo do trabalho e/ou mercado de trabalho. A partir da análise dos Projetos Pedagógicos de Cursos (PPC's) e de entrevistas com coordenadores de curso buscamos responder se os currículos podem se fundamentar numa perspectiva de formação crítica dos discentes, que aspirasse a emancipação social dos sujeitos ou se limitam a uma formação rápida para a inserção no mercado de trabalho. A pesquisa permitiu reconhecer a existência de concepções de Educação Profissional referenciadas tanto para o mundo do trabalho como para o mercado, apontando também as dificuldades para a conciliação entre as duas concepções de formação.

Palavras chave: concepções; mundo do trabalho; mercado de trabalho.

\section{RESUMES OF SUBSEQUENT/CONCOMITANT TECHNICAL COURSES OF IFSUDESTE-MG: TRAINING FOR THE MARKET OR FOR THE WORLD OF WORK?}

\begin{abstract}
This article analyzes curricula of subsequent/concomitant courses of IFSUDESTEMG/Campus Juiz de Fora, identifying elements that indicate conceptions of Professional Education referenced for the world of work and/or labor market. From the analysis of the Pedagogical Projects of Courses (PPC's) and interviews with course coordinators we seek to answer whether the curricula can be based on a perspective of critical training of students, which aspires to the social emancipation of subjects or are limited to a rapid formation for insertion in the labor market. The research allowed us to recognize the existence of conceptions of Professional Education referenced both for the world of work and for the market, also pointing out the difficulties for the reconciliation between the two conceptions of formation.
\end{abstract}

Keywords: conceptions; world of work; labour market.

\footnotetext{
${ }^{1}$ Instituto Federal de Educação, Ciência e Tecnologia do Sudeste de Minas Gerais. E-mail: anelisa.quintao@ifsudestemg.edu.br

${ }^{2}$ Instituto Federal de Educação, Ciência e Tecnologia do Sudeste de Minas Gerais. E-mail: ataualpa.oliveira@ifsudestemg.edu.br
} 


\section{INTRODUÇÃO}

Este estudo apresenta o resultado da investigação de currículos de cursos subsequentes/concomitantes do IFSUDESTE-MG/Campus Juiz de Fora, em que se identificou elementos que indicam concepções de Educação Profissional referenciadas para o mundo do trabalho e/ou mercado de trabalho na construção e condução dos mesmos. Elaborado a partir da pesquisa de mestrado realizada no Programa de Pós-graduação em Educação Profissional e Tecnológica (PROFEPT) do Instituto Federal de Educação Ciência e Tecnologia do Sudeste de Minas Gerais-Campus Rio Pomba, cuja dissertação foi defendida em 2020.

A relevância da investigação se deu a partir das reflexões a cerca do papel social desempenhado pela educação, baseadas em Freire (1996). Considerando a educação como instrumento de desenvolvimento da autonomia, o autor discorre sobre a prática pedagógica e a formação de sujeitos para sua inserção no mundo criticamente, de forma a atender não apenas as expectativas econômicas do mercado de trabalho, mas o desenvolvimento em sua plenitude. Esta questão converge com o conceito amplo de trabalho apresentado por Saviani (2003), em que o termo é entendido como um processo de humanização, em que o homem atua sobre a natureza, a transformando para satisfazer suas necessidades. Neste sentido, trabalho não se reduz à atividade remunerada, mas toda ação do homem visando garantir sua existência.

Os estudos no mestrado profissional apresentaram o conceito de formação integral dos sujeitos na Educação Profissional, apontando esta em cursos técnicos integrados ao Ensino Médio. Entretanto, surgiu a indagação sobre a possibilidade de tal formação também em cursos subsequentes/concomitantes; uma vez que a mesma pode contribuir para emancipação dos sujeitos e trazer uma nova interpretação sobre a Educação Profissional. Ao se pensar em Educação Profissional, muitas vezes associamos como preparação para o mercado de trabalho, sem a necessária reflexão sobre a finalidade da educação. Desta forma, a investigação pode contribuir para que a intuição considere a relevância da formação humana dos discentes e construa currículos que articulem a preparação para o mercado com a formação para o mundo de forma crítica.

A pesquisa, de natureza qualitativa, utilizou referencial bibliográfico atualizado para fundamentar as diferentes concepções de formação, fornecendo elementos a serem utilizados 
como inferência na classificação das categorias mundo do trabalho e mercado de trabalho durante a análise dos dados coletados na pesquisa de campo.

Para analisar as categorias mundo e mercado de trabalho é imprescindível resgatar o papel assumido pelo trabalho dentro do contexto capitalista. Frigotto (2009) mostra a perda do caráter ontológico $^{3}$ do trabalho em nossa sociedade, em que trabalho é visto numa visão reducionista como sinônimo de emprego. Segundo o autor:

Com o desenvolvimento do modo de produção capitalista, o trabalho, na sua dimensão ontológica, forma específica da criação do ser social, é reduzido a emprego - uma quantidade de tempo vendida ou trocada por alguma forma de pagamento" (FRIGOTTO, 2009, p. 176).

De acordo com Saviani (2003, p.133) "trabalhar não é outra coisa senão agir sobre a natureza e transformá-la". O trabalho está diretamente relacionado com o processo de humanização uma vez que "o homem se constitui como tal à medida que necessita produzir continuamente sua própria existência" (p. 132), a natureza não a garante, cabendo ao homem atuar sobre ela, ajustando-a às suas necessidades, às suas finalidades. Esta definição assume o sentido ontológico do trabalho. A categoria mundo do trabalho se referencia à partir deste sentido, enquanto mercado de trabalho, se relaciona com a historicidade do mesmo.

No decorrer do desenvolvimento do sistema capitalista, o trabalho perde o seu valor de uso e passa a ser concebido como uma mercadoria, prevalecendo o valor de troca, que visa à obtenção de lucro e manutenção do capital. Ciavatta e Ramos (2011), fazem a distinção entre os termos mercado de trabalho e mundo do trabalho, enfatizando que o primeiro se restringe à ocupação de postos de trabalho na situação de compra e venda desta força. Já o segundo teria um caráter mais abrangente, que reflete o trabalho amplamente; o reflexo do mesmo na vida do trabalhador, sua condição de classe, a historicidade e as condições de desenvolvimento desta atividade.

Araújo e Rodrigues (2010) definem dois tipos de educação, alicerçadas nas pedagogias do trabalho ou do capital. A primeira estaria voltada para conformação com a realidade, enquanto a segunda aspira a transformação social. Defendem a pedagogia do trabalho, apresentando a necessidade da práxis na formação profissional, sendo o trabalho orientador das

\footnotetext{
${ }^{3}$ FRIGOTTO, G. Trabalho. In: FUNDAÇÃO OSWALDO CRUZ. ESCOLA POLITÉCNICA DE SAÚDE JOAQUIM VENÂNCIO (Org.). Dicionário da educação profissional em saúde. Rio de Janeiro: Fundação Oswaldo Cruz, Escola Politécnica de Saúde Joaquim Venâncio, 2009.p.399.
} 
ações formativas do homem. Para eles, a educação deve servir para a emancipação, de foram que o trabalhador seja instrumentalizado para dominar as esferas produtivas, culturais e da vida social. Diferente do que acontece na pedagogia tecnicista ou das competências que seriam pedagogias do capital.

O reconhecimento da existência desses dois projetos antitéticos de formação de trabalhadores impõe que se faça uma opção entre eles, tal como sugere Frigotto na epígrafe deste texto. Não se trata apenas de uma opção entre duas pedagogias, é mesmo uma opção entre duas filosofias, duas leituras de mundo, de sua dinâmica e de seu futuro. Para Marx (apud VASQUEZ, 1968) existem dois tipos de filosofia: aquelas que se propõem a explicar a realidade (filosofia como acomodação ao mundo) e aquelas que servem à transformação do mundo (filosofia como guia da transformação humana radical) (ARAÚJO E RODRIGUES, 2010, p. 52).

A construção dos currículos da Educação Profissional não pode se omitir da urgente reflexão sobre esta questão uma vez que pode ficar subordinada aos interesses do sistema produtivo. Assim como aponta Dante (2014), a educação brasileira se constituiu em uma dualidade, oferecendo formações diversificadas para aqueles que irão executar atividades intelectuais ou manuais. É preciso buscar uma educação que não reproduza as desigualdades e vise apenas a manutenção deste sistema. A escola é um espaço de desenvolvimento pleno dos sujeitos, para o pensar e compreender o mundo.

Desse modo, compreende-se que a histórica dualidade estrutural na esfera educacional não é fruto da escola, mas da sociedade dual/cindida em que se vive, por imposição do modo de produção capitalista. Nesse sentido, exige-se da escola que esta se estruture de forma dual no sentido de fortalecer o modo de produção do capital que se baseia na valorização diferenciada do trabalho intelectual e do trabalho manual, do trabalho simples e do trabalho complexo. Portanto, romper completamente a dualidade estrutural da educação escolar não depende apenas do sistema educacional, mas antes da transformação do modo de produção vigente (DANTE, 2014, p.14).

O conceito de politecnia, apresentado por Saviani (2003), traz uma proposta de superação desta dicotomia, em que a instrução profissional e a geral não podem ser vistas de forma separadas. Concebe uma relação indissolúvel entre trabalho manual e intelectual e ressalta que:

Se o homem se constitui a partir do momento em que age sobre a natureza, adaptando-a a si, ajustando-a as suas necessidades (e ajustar as necessidades significa plasmar a matéria, a realidade, segundo uma intenção, segundo um objetivo, que é antecipado mentalmente), então o exercício da função 
intelectual já está presente nos trabalhos manuais os mais rudimentares, os mais primitivos. A separação dessas funções é um produto histórico-social e não é absoluta, mas relativa (SAVIANI,2003, p.138).

Saviani (2003, p.140) define politecnia como “domínio científico das diferentes técnicas que caracterizam o processo de trabalho produtivo moderno". Tal domínio instrumentalizaria o trabalhador para desenvolver as diferentes modalidades de trabalho, compreendendo sua essência. Identifica-se uma concepção de formação para o mundo do trabalho, pois este seria a vida humana que se constitui pelo trabalho.

Supõe-se que, dominando esses fundamentos, esses princípios, o trabalhador está em condições de desenvolver diferentes modalidades de trabalho, com a compreensão de seu caráter, de sua essência. Não se trata de um trabalhador adestrado para executar com perfeição determinada tarefa e que se encaixe no mercado de trabalho para desenvolver aquele tipo de habilidade. Diferentemente, trata-se de propiciar um desenvolvimento multilateral, um desenvolvimento que abarca todos os ângulos da prática produtiva na medida em que ele domina aqueles princípios que estão na base da organização da produção moderna (SAVIANI, 2003, p.140).

Frigotto (2009), reconhece as contradições presentes no sistema capitalista, mas defende a possibilidade de se pensar uma educação omnilateral e unitária; capaz de permitir aos indivíduos compreender o mundo e também atender às necessidades do processo produtivo. Esta visaria o desenvolvimento integral dos sujeitos, não formando trabalhadores apenas para executar, mas que sejam capazes de pensar o trabalho.

Entretanto, se sairmos do campo da antinomia, ciência e tecnologia ou pura negatividade ou pura positividade e lidarmos com o plano das contradições no seio do capitalismo realmente existente e, portanto, com situações concretas e forças em disputa, não me parece que se trate de uma ilusão a possibilidade de os educadores disputarem, dentro da perspectiva da escola unitária e educação omnilateral, as novas bases de conhecimento demandados pelo processo produtivo (FRIGOTTO, 2009, p. 186-187).

Uma Educação Profissional fundamentada na politecnia, e omnilateralidade concebe o trabalho como a atividade humana sobre a natureza para produzir sua existência, que se faz não apenas no emprego como busca de meio de subsistência, mas nas mais diversas ações que executa de forma planejada e que são essenciais para sua vida. Portanto, estaria fundamentada numa concepção de formação para o mundo do trabalho. Nesta, o currículo não seria instrumento de reprodução social ou prescrição de conteúdos, mas prática cultural que se dá na escola "na tentativa de captar os conceitos que fundamentam a realidade nas relações que a 
constituem" (Ramos, 2016, p.5). Entretanto, muito tem se refletido sobre esta proposta nos cursos técnicos integrados ao Ensino Médio, enquanto nos cursos técnicos subsequentes/ concomitantes, a relevância do desenvolvimento integral dos sujeitos é pouco discutida.

Observa-se o uso do termo integração com frequência por diversos autores quando tratam da forma de Educação Profissional integrada ao Ensino Médio dentro de um mesmo currículo. Ciavatta e Ramos (2011), apontam o caráter abrangente do termo, acreditando que a formação humana, politécnica e omnilateral pode ser considerada também em outras formas de oferta da Educação Profissional. Tal termo remete a uma pedagogia histórico-crítica, que propicia aos trabalhadores compreenderem as relações que se estabelecem no processo de produção de sua existência e promovem a emancipação social.

O primeiro sentido que atribuímos à integração expressa uma concepção de formação humana que preconiza a integração de todas as dimensões da vida o trabalho, a ciência e a cultura - no processo formativo. Tal concepção pode orientar tanto a educação geral quanto a profissional, independentemente da forma como são ofertadas. O horizonte da formação, nessa perspectiva, é a formação politécnica e omnilateral dos trabalhadores e teria como propósito fundamental proporcionar-lhes a compreensão das relações sociais de produção e do processo histórico e contraditório de desenvolvimento das forças produtivas (CIAVATTA e RAMOS, 2011, p. 31, grifos nossos).

No estudo, buscou-se averiguar se as concepções de formação para o mundo e o mercado de trabalho podem caminhar juntas e quais os tipos de conflitos e dificuldades encontradas, verificando se nos currículos existe articulação entre a formação humana integral dos sujeitos e a preparação para desempenhar funções no emprego. Verificou a presença de elementos que indicassem aspirações emancipatórias na formação dos discentes, que visassem à compreensão do mundo do trabalho e não apenas a venda da força de trabalho para garantir a empregabilidade. Investigou as questões: Os currículos dos cursos técnicos subsequentes/concomitantes podem se fundamentar numa perspectiva de educação para o mundo do trabalho criticamente ou se limitam a uma formação rápida para a inserção no mercado de trabalho com caráter profissionalizante? Nesta forma de oferta do ensino técnico, considera-se o desenvolvimento da autonomia dos sujeitos para utilizarem os conhecimentos produzidos em suas relações com o mundo?

A formação para o mundo do trabalho aqui é entendida como aquela que supera a visão mercadológica da profissionalização; entendendo que a preparação para o mercado deve estar inserida dentro do currículo, entretanto, a forma como se dá esta preparação é que pode definir 
se esta educação pode formar para o mundo do trabalho. Formar para o mundo seria propiciar condições para que os educandos compreendam o trabalho e as relações que se estabelecem neste processo no sistema capitalista, dando a estes sujeitos consciência de classe, de forma que façam uma leitura crítica do mundo capitalista. Assim como apresentada por Araújo e Rodrigues (2010) a educação transformadora se volta para a emancipação dos sujeitos e busca o desenvolvimento da capacidade de pensar, produzir e transformar; não apenas fazer. Ela qualifica, valoriza o trabalhador e fortalece a classe politicamente.

\section{PERCURSO METODOLÓGICO}

A pesquisa foi desenvolvida a partir de uma abordagem qualitativa, exploratória e descritiva; utilizando pesquisa bibliográfica, documental e de campo. Tal escolha foi motivada natureza interpretativa da investigação, em que se buscou embasamento teórico para analisar o conteúdo dos discursos presentes nos documentos (Projetos pedagógicos de cursos) e nas entrevistas com os coordenadores de cursos. Estes documentos foram selecionados como objetos, por serem os principais orientadores na organização da estrutura curricular dos cursos. Enquanto, os coordenadores foram participantes nas entrevistas pelo papel fundamental que desempenham na construção dos documentos.

A partir da discussão teórica baseada em Ramos (2016) Ciavatta e Ramos (2011); Saviani (2003); Araújo e Rodrigues (2010); Frigotto (2006) e (2009); Mészáros (2008), Dante (2014); Freire (1996) se resgatou os sentidos do trabalho, seu papel definido na sociedade e as relações que se estabelecem nos modos de produção e sistemas econômicos em que se insere. Este referencial embasou a elaboração de um quadro com termos e expressões que diferenciam as categorias mundo do trabalho e mercado de trabalho, que possibilitou a classificação do conteúdo encontrado nas pesquisas documental e de campo. Além disso, orientou a elaboração do roteiro para entrevista semiestruturada, indicando perguntas pertinentes para se averiguar o objeto de estudo. O Quadro 1 demonstra diferencial elaborado: 
Quadro 1 - Classificação de termos e expressões que referenciam as categorias analisadas

\begin{tabular}{|c|c|}
\hline $\begin{array}{c}\text { MERCADO DE TRABALHO } \\
\text { sinônimo de emprego }\end{array}$ & MUNDO DO TRABALHO \\
\hline Polivalência & $\begin{array}{c}\text { Prabalho } \rightarrow \text { criação do ser social, que atua sobre a } \\
\text { natureza para satisfazer suas necessidades. }\end{array}$ \\
\hline Competências & Omnilateralidade \\
\hline Empregabilidade & Educação Integral \\
\hline Cidadão produtivo & Cidadania coletiva \\
\hline Eficiência & Compreensão \\
\hline Produtividade & Criticidade \\
\hline Sociedade do conhecimento & Desenvolvimento de todas as potencialidades \\
\hline Educar para competência & Educar para cidadania \\
\hline Competitividade & Solidariedade \\
\hline Valor de troca & Valor de uso \\
\hline Mérito & Direito \\
\hline Habilidades & Autonomia \\
\hline Subordinação ao capital & Conscientização/compreensão de mundo \\
\hline Submissão às forças produtivas & Integração às forças sociais \\
\hline & \\
\hline &
\end{tabular}

Fonte: Elaborado pela autora

A pesquisa documental analisou e descreveu as concepções de Educação Profissional redigidas em documentos norteadores dos currículos de cursos técnicos da modalidade subsequente/concomitante, os Projetos Pedagógicos de Cursos. Na pesquisa de campo, procedeu-se da mesma forma com os discursos de sujeitos diretamente envolvidos com o objeto de estudo, dentre eles, os coordenadores de cursos. Estes forma escolhidos, por serem os agentes principais que conduzem a construção dos documentos. Tais discursos foram oriundos de entrevistas semiestruturadas, individuais e com perguntas abertas, elaboradas após o estudo bibliográfico. Buscou-se interpretar em qual perspectiva de formação profissional estão fundamentadas, seguindo o roteiro de entrevista (Quadro 2), que foi desmembrado em seis itens de análise: 
Quadro 2 - Roteiro de entrevista com os coordenadores de curso

\begin{tabular}{|c|c|}
\hline Itens analisados & Perguntas realizadas \\
\hline $\begin{array}{l}\text { 1. Atuação e formação } \\
\text { dos coordenadores }\end{array}$ & $\begin{array}{l}\text { Qual sua idade? Há quanto tempo trabalha com a Educação } \\
\text { Profissional? Qual sua formação? Possui formação } \\
\text { pedagógica? Participa de formação continuada sobre a } \\
\text { Educação Profissional e o processo de ensino- } \\
\text { aprendizagem? }\end{array}$ \\
\hline $\begin{array}{l}\text { 2. Finalidade da Educação } \\
\text { Profissional e } \\
\text { tecnológica nos cursos } \\
\text { técnicos subsequentes/ } \\
\text { concomitantes de nível } \\
\text { médio }\end{array}$ & $\begin{array}{l}\text { Os cursos técnicos subsequentes/concomitantes possuem } \\
\text { uma demanda de jovens e adultos que buscam qualificação } \\
\text { profissional. O que este público espera dos cursos } \\
\text { técnicos? Qual o papel da Educação Profissional oferecida } \\
\text { nos cursos técnicos subsequentes no contexto social } \\
\text { brasileiro? }\end{array}$ \\
\hline $\begin{array}{l}\text { 3. Sentidos do trabalho } \\
\text { (ontológico/histórico) }\end{array}$ & $\begin{array}{l}\text { O que você considera por trabalho? Como o curso técnico } \\
\text { pode ajudar os alunos neste sentido? }\end{array}$ \\
\hline $\begin{array}{l}\text { 4. Educação } \\
\text { emancipatória }\end{array}$ & $\begin{array}{l}\text { Existem disciplinas/conteúdos que tratam das relações } \\
\text { sociais que se estabelecem no trabalho e possam promover } \\
\text { a reflexão crítica do trabalhador com o desenvolvimento } \\
\text { da consciência de classe? No processo de ensino- } \\
\text { aprendizagem os conhecimentos são contextualizados em } \\
\text { experiências dos sujeitos em suas relações como o mundo } \\
\text { e suas vivências? Na grade dos cursos há disciplinas que } \\
\text { se envolvem com a formação humana dos } \\
\text { alunos/trabalhadores para além da técnica? Há } \\
\text { preocupação com a emancipação dos sujeitos nos cursos } \\
\text { técnicos subsequente/concomitantes? Acredita que } \\
\text { enquanto pública a educação técnica dos cursos } \\
\text { subsequentes/concomitantes do IF deve ter a preocupação } \\
\text { com a formação política dos alunos? }\end{array}$ \\
\hline 5. Pedagogias & $\begin{array}{l}\text { Para você, o que é ensinar? Como se dá esta relação entre } \\
\text { professor e aluno? Qual o papel de cada um neste } \\
\text { processo? Os cursos técnicos subsequentes/concomitantes } \\
\text { formam trabalhadores para atender as necessidades do } \\
\text { mercado e se manterem empregados ou se desenvolverem } \\
\text { criticamente e lutar pela transformação social? }\end{array}$ \\
\hline
\end{tabular}




\begin{tabular}{|l|l|}
\hline 6. Currículo & $\begin{array}{l}\text { Como os conteúdos de ensino são selecionados? Em que } \\
\text { se baseiam as escolhas? Nos PPCs há conteúdos que visam } \\
\text { à formação humana? Há espaço nos PPCs para incluir } \\
\text { disciplinas que abordem a formação humana crítica e } \\
\text { política destes trabalhadores? Considera relevante tal } \\
\text { formação? Acredita que a participação de outros membros } \\
\text { da comunidade escolar poderia contribuir na construção } \\
\text { dos PPCs? }\end{array}$ \\
\hline
\end{tabular}

Fonte: Elaborado pela autora

Ao traçar o perfil dos entrevistados observou-se que as idades estão na faixa de 38 a 46 anos e que já possuem experiência significativa em Educação Profissional como professores. Porém, na função de coordenadores, a experiência é mais reduzida, um deles tem apenas um ano na função, o outro há dois e o terceiro já faz quatro anos na coordenação. As formações concentram-se em cursos voltados para a área técnica, sendo dois doutores na área e um com duas especializações, apesar de um deles possuir o curso de Licenciatura em Física. Constatouse que não existe a formação continuada desses profissionais com especificidades para a Educação Profissional, pois relatam que não participam e um deles diz fazer leituras por conta própria. A falta de conscientização da instituição quanto à necessidade de formação continuada dos profissionais sobre as especificidades desta modalidade de ensino para buscar o aprimoramento das práticas pedagógicas, pode ser inferida nestes discursos. Há de se pensar que grande parte dos professores que ingressam para dar aula nas áreas técnicas não possui formação pedagógica, sendo carentes de conhecimento a respeito da proposta de uma formação integral dos sujeitos, o que pode levá-los a reproduzir um processo de ensino baseado em suas experiências enquanto alunos, sem a necessária reflexão crítica sobre a prática docente.

$\mathrm{Na}$ investigação dos Projetos Pedagógicos de Curso foram considerados os seguintes itens que constituem os textos: apresentação do curso, histórico da instituição, justificativa do curso, perfil profissional, campos de atuação, objetivos do curso, objetivos específicos e estrutura curricular (carga horária e componentes curriculares). Em cada item buscou-se identificar mensagens que apontassem concepções de formação para o mercado de trabalho ou mundo do trabalho, tendo como referência o quadro diferencial construído (quadro 1).

Foram escolhidos cinco cursos para a amostra, dentre os onze que o campus possui na modalidade subsequente/concomitante; devido a maior proximidade da pesquisadora com os mesmos, em que atua como orientadora e supervisora desde o ano de 2017, entre eles: Eletrotécnica, Eletromecânica, Eletrônica, Metalurgia e Mecânica. Os cursos foram escolhidos 
a partir da classificação no eixo tecnológico Controle e processos industriais. Tal eixo é diretamente voltado para a formação de profissionais para a indústria, o que pode influenciar a constituição de currículos referenciados para o mercado de trabalho, o que tornou relevante investigar em qual perspectiva se dá esta formação. Os Projetos Pedagógicos dos cinco cursos foram objeto de análise e houve a participação de três coordenadores nas entrevistas. Os entrevistados assinaram Termo de Consentimento Livre e Esclarecido, no qual consta o número de CPF e assinatura dos mesmos. Em cumprimento aos termos de sigilo estabelecidos no Termo de Consentimento Livre e Esclarecido, ao longo do artigo as falas dos entrevistados aparecem desidentificadas assim como o conteúdo dos documentos. Para a condução da discussão na entrevista foi utilizado o Roteiro para Entrevista semiestruturada (quadro 2), já apresentado anteriormente.

Os dados obtidos a partir dos documentos (PPC's) e das entrevistas foram submetidos à análise de conteúdo, investigando as mensagens que se manifestaram nestas situações comunicativas. Segundo Bardin (2011, p.44) "a análise de conteúdo aparece como um conjunto de técnicas de análise das comunicações que utiliza procedimentos sistemáticos e objetivos de descrição do conteúdo das mensagens. Mas isso não é suficiente para definir a especificidade da análise de conteúdo". O autor aponta a necessidade de complementar as definições buscando o contexto da produção das mensagens apontando que "A intenção da análise de conteúdo é a inferência de conhecimento relativo às condições de produção (ou, eventualmente de recepção), inferência esta que recorre a indicadores (quantitativos ou não)". No processo da análise do conteúdo haverá três fases: a descrição, a inferência e a interpretação. Conforme Bardin:

Se a descrição (a enumeração das características do texto, resumida após tratamento) é a primeira etapa necessária e se a interpretação (a significação concedida a estas características) é a última fase, a inferência é o procedimento intermediário, que vem permitir a passagem, explícita e controlada, de uma à outra (BARDIN, 2011, p. 45).

A análise das mensagens dos textos orais e escritos trouxe uma interpretação acerca do tema investigado (concepções de Educação Profissional), sendo feita a análise categorial. Os textos se desmembraram nas categorias de análise mundo de trabalho e mercado de trabalho, com critério semântico (atribuição de significado ao tema para agrupar em categoria); adotando indicadores como a presença ou ausência de determinados elementos da mensagem, levando em conta o contexto da mensagem. A inferência se deu a partir da presença do índice de análise 
(tema ou palavra) baseada na pesquisa bibliográfica que possibilitou a diferenciação as categorias para a classificação do conteúdo dos discursos.

Estabeleceu-se uma comparação entre as interpretações realizadas na análise das duas fontes de dados. Averiguou-se a existência de semelhanças entre as concepções, se os documentos retratavam a percepção dos coordenadores em relação às categorias mundo do trabalho e mercado de trabalho. Considerando os diversos itens analisados nas fontes, os elementos encontrados foram comparados e agrupados em três eixos principais que ressaltam as concepções de formação dentro de cada categoria, sendo eles: sentidos do trabalho, papel da instituição e estruturação curricular. Os resultados encontrados, apresentam-se a seguir.

\section{RESULTADOS E DISCUSSÕES}

\section{OS SENTIDOS DO TRABALHO NOS CURRÍCULOS}

A Educação Profissional se relaciona diretamente com o trabalho. Entretanto, o termo trabalho pode assumir significados diferentes, em virtude do contexto em que estiver inserido. Pode-se considerar o seu sentido ontológico, enquanto atividade produtora da existência humana. Neste caso, estaria dentro de uma perspectiva de mundo, uma vez que leva em conta qualquer ação humana realizada pelo sujeito visando a garantia de sua sobrevivência. Mas também pode assumir o sentido histórico, que se constitui pela influência do sistema econômico vigente, atualmente o sistema capitalista; o que associa o termo a uma perspectiva de mercado.

Segundo Frigotto (2009, p. 176) "com o desenvolvimento do modo de produção capitalista, o trabalho, na sua dimensão ontológica, forma específica da criação do ser social, é reduzido a emprego - uma quantidade de tempo vendida ou trocada por alguma forma de pagamento". Desta forma, classifica-se dentro da categoria mundo do trabalho as concepções de formação que relevam o sentido ontológico do termo e na categoria mercado de trabalho aquelas que se baseiam no sentido histórico capitalista, em que trabalho se torna sinônimo de atividade remunerada.

A análise dos dados obtidos na investigação dos Projetos Pedagógicos de Cursos e nas entrevistas com os coordenadores de cursos classificaram o conteúdo dos discursos dentro da categoria mercado de trabalho. A apresentação dos cursos nos PPC's, traz as expressões como 
"necessidade de qualificação de mão de obra", "preparação deste profissional com as habilidades requeridas pelo mercado" e "demandas por mão de obra". $\mathrm{Na}$ fala dos coordenadores encontram-se os seguintes discursos:

Entrevistado 1- "Entendo trabalho como atividade remunerada".

Entrevistado 2- "Uma atividade inerente as pessoas e elas prestam este serviço tendo uma contrapartida, normalmente financeira".

Entrevistado 3- "Uma formação imediata para trabalhar, buscar um emprego".

Observa-se que o termo trabalho é reduzido ao conceito de emprego, em que o trabalhador deve ser preparado para atender as necessidades do mercado e assim receber uma remuneração pelo serviço prestado.

Os campos de atuação citados nos documentos, não revelam reflexão sobre os usos do conhecimento nas interações dos sujeitos nas diversas relações com o mundo, se restringindo ao mercado de trabalho uma vez que entre os locais predominam-se indústrias, laboratórios e empresas. Esta limitação também é percebida na fala dos entrevistados quando relatam que os discentes:

Entrevistado 1- "Esperam uma boa qualificação para ter ascensão profissional e ingressar no mercado de trabalho".

Entrevistado 2- "Querem ter a oportunidade de trabalhar e conseguir as coisas deles lá fora".

Entrevistado 3- "Grande maioria procura qualificação, abrir portas para iniciar a carreira em uma empresa, ou ter promoção, quanto já estão na empresa".

Desta forma, consideram que a expectativa dos discentes com a Educação profissional é a de inserção no mercado através da qualificação; não percebendo que os conhecimentos podem ser aplicados em atividades não remuneradas, sendo também trabalho, independente de emprego.

A caracterização do trabalhador como polivalente ou politécnico também permite associar às categorias mercado ou mundo do trabalho, uma vez que o primeiro considera o indivíduo capaz de exercer várias funções, sem o aprofundamento no domínio do conhecimento científico, com uma formação integral, como aconteceria com o segundo. Nos PPC's observase o conceito de formação do trabalhador polivalente ao discorrer sobre a possibilidade do exercício de várias funções. Dois coordenadores revelam desconhecimento sobre termo 
politecnia associando o termo à diversidade de conteúdos técnicos, sem refletir sobre a compreensão crítica do processo produtivo pelo discente ao falar:

Entrevistado 1- "Tem ligação com a diversidade de conteúdos ministrados”. Entrevistado 2- "É a preparação para a área técnica, para o mercado.

Estes discursos não consideram a formação para "o domínio do conhecimento científico sobre as diferentes técnicas que caracterizam o processo de trabalho" (Saviani,2003, p. 140), o que aconteceria numa concepção de formação para o mundo do trabalho.

Araújo e Rodrigues (2010) ressaltam que na lógica do capital, o indivíduo deve ser adestrado, acomodado, empregável e disponível no mercado. Há uma divisão social e técnica do trabalho para garantir a sobrevivência do capital; com mão-de-obra sempre disponível. A educação propiciaria apenas os requisitos mínimos para os trabalhadores atenderem a demanda do mercado. Por isso deve-se tomar cuidado quando se tem uma visão reducionista do trabalho, ignorando seu caráter ontológico.

\section{O PAPEL DA EDUCAÇÃo PROFISSIONAL NOS DOCUMENTOS E NOS DISCURSOS}

A definição da finalidade da Educação Profissional influencia a constituição de currículos referenciados na formação para o mundo do trabalho ou para o mercado de trabalho. Uma proposta de educação que considere o papel social desempenhado por esta modalidade de ensino pode se enquadrar na categoria mundo do trabalho, enquanto aquela que se restringe a função econômica da mesma para atender a expectativa do capital, estaria dentro de mercado de trabalho. A contribuição que a educação poderia dar para a transformação da sociedade é apresentada por Mészáros (2008), ao considerar esta como um instrumento de esclarecer, instruir e informar sobre a situação de opressão e instigar o educando a se posicionar diante do contexto de injustiça e desigualdade social nesta sociedade capitalista.

As concepções à cerca do papel desempenhado pela Educação Profissional tanto nos documentos quanto nos discursos indicaram consciência sobre a finalidade social da mesma. Observa-se no histórico da Instituição (parte integrante dos Projetos Pedagógicos de Cursos), a visão da formação cidadã, abrangendo o desenvolvimento humano e social dos discentes, onde discorrem que os Institutos buscam "formar e qualificar cidadãos para atuar nos diversos setores 
da economia". A palavra cidadão traz a ideia de uma formação humana e social para além do trabalho técnico. Dois documentos ainda complementam com o conceito pelo de cidadania, enfatizando a atuação social dos jovens com valores morais ao dizerem "torna-se cada vez mais importante o papel do campus Juiz de Fora nessa frente ampla pela educação pública, gratuita e de qualidade cujo horizonte é de sempre ser o alcance da cidadania plena dos jovens que almejam um futuro melhor ao ingressar em seus mais variados cursos, e prepará-los para intervir em seus meios sociais, com responsabilidade, pautados pela ética e o bem comum da sociedade". Aparece também o elemento solidariedade, constituindo assim uma concepção de formação para o mundo do trabalho. Na fala dos coordenadores, a Educação Profissional é vista como ampliadora da visão crítica dos discentes, considerando a relevância da formação humana, com preparação dos sujeitos para a vida. Observa-se este fato quando os entrevistados relatam:

Entrevistado 1- "Preparar os jovens para o mercado e ampliar a visão, entram focados, pensando uma coisa e depois enxergam outras possibilidades, ampliar horizontes".

Entrevistado 2- "O mercado de trabalho é cru, é muito duro, mas as pessoas devem ter condições de se desenvolver, tem objetivos e metas na vida para alcançar, então a escola tem que proporcionar isso, para que as pessoas possam fazer o que quiserem da vida delas".

A perspectiva do papel econômico desempenhado pela Educação Profissional, também se faz presente nos discursos, apontando para a categoria de formação para o mercado de trabalho. Na fala de um coordenador é citado o desenvolvimento de competências e habilidades, em que o mesmo cita que a Educação Profissional deve:

Entrevistado 3- "Fornecer competências para o aluno desempenhar as atividades no mercado".

Esta questão também se apresenta frequentemente no decorrer dos textos analisados, com destaque no perfil profissional, em que o termo competência é citado nos cinco PPC's. Identifica-se neste caso, a predominância da Pedagogia das Competências apresentada por Araújo e Rodrigues (2010). Segundo eles, ela se constitui de ações pontuais de curta duração com formação focada em requerimentos emergenciais do mercado. Não ensina a aprender e nem a transferência de capacidades. Tal pedagogia desconsidera o contexto histórico, social e cultural do processo de trabalho. O objetivo é a posse de competências pelo aluno e seu desenvolvimento é uma construção pessoal.

Nas justificativas dos cursos encontradas nos projetos, predominam a formação para o mercado. Os cinco discursos ressaltam a necessidade de qualificar os trabalhadores para atender 
a demanda do sistema produtivo; o que se afina com o discurso dos entrevistados em relação às expectativas dos sujeitos, citadas anteriormente. Neste sentido, há de se pensar nas colocações de Freire, em que critica a formação que atende aos interesses dos donos do capital, com uma formação fragmentada, que não contribui para o desenvolvimento pleno dos sujeitos.

Naturalmente, reinsisto, $\mathrm{O}$ empresário moderno aceita, estimula e patrocina o treino técnico de seu operário. $\mathrm{O}$ que ele necessariamente recusa é a sua formação que, envolvendo o saber técnico e científico indispensável, fala de sua presença no mundo. Presença humana, presença ética, aviltada toda vez que transformada em pura sombra (FREIRE, 1996, p. 102.)

Desta forma, os trabalhadores ficariam submissos às forças produtivas e não integrados às forças sociais, como poderia ocorrer em uma formação para o mundo do trabalho. Os cursos acabam se justificando a partir do caráter econômico e ignorando o caráter social da formação dos educandos.

Analisando os objetivos do curso, encontrados nos documentos, encontram-se elementos de formação para o mundo do trabalho ao enfatizar o papel social do trabalho e a relevância do desenvolvimento crítico dos trabalhadores, de forma a lidar não apenas com a questão técnica; mas também política, socioeconômica, ambiental e cultural. Este fato é indicado quando os documentos trazem que " tem-se como objetivo formar um profissional qualificado capaz de exercer diversas funções dentro da sociedade", "proporcionar uma atuação baseada no senso crítico e no exercício constante da criatividade, na identificação e resolução de problemas, tais recursos devem ser usados para lidar com questões técnicas, políticas, socioeconômicas, ambientais e culturais, com uma visão ética e humanística em prol da sociedade", " além de possuir em orientação moral compatível com sua função no contexto social”. Ao se investigar os conhecimentos de termos de Educação Integral que os coordenadores possuem, verificou-se também a existência desta concepção, ao associar omnilateralidade a uma formação mais abrangente, que não se restringe ao ensino do conteúdo técnico. Entre as falas destaca-se:

Entrevistado 1- "Acho que é uma formação mais abrangente, uma formação ampla em relação as disciplinas que o sujeito estuda de uma forma geral, uma formação concatenada, que não é dispersa, onde as disciplinas e conteúdos podem conversa".

Entrevistado 2- "Este termo é muito utilizado, mas na minha visão, além de trabalhar as especialidades técnicas, é formar para além, uma formação ampla, não apenas técnica, mas para a vida de forma geral". 
Nos objetivos específicos, os PPC's revelam concepções de formação para o mercado de trabalho, com a presunção de desenvolver competências e aptidões; assim como para o mundo do trabalho, ao discorrerem sobre a formação cidadã e crítica para a atuação na sociedade, também utilizando verbos que exigem autonomia e compreensão para designar atividades do trabalhador.

Para Araújo e Rodrigues (2010) a educação pode ser de dois tipos: para a conformação com a realidade ou para a transformação social. Teríamos então uma pedagogia do capital e uma do trabalho. As concepções pedagógicas que constituíram os discursos analisados perpassaram pelas diversas teorias curriculares; com as pedagogias Tecnicista, Das competências e Histórico-crítica. As duas primeiras seriam pedagogias do capital e a última do trabalho. Assim conclui-se que são classificadas tanto na categoria de formação para o mundo quanto para o mercado de trabalho.

A pedagogia tecnicista pode ser identificada quando dois dos entrevistados centram o processo de ensino no professor, como protagonista que transmite o conhecimento organizado de forma sistemática, ao dizerem:

Entrevistado 1- "Ensinar é fornecer ao aluno condições para aprender o conteúdo".

Entrevistado 2- "Para mim, ensinar é multiplicar o conhecimento adquirido para que os alunos possam realizar suas tarefas com honestidade e dignidade, também traz valores".

Também pode ser identificada nos PPC's, em que os conteúdos organizados sequencialmente por disciplinas ou temas fragmentados. Neste currículo, desconsidera-se o papel do discente, devendo o mesmo seguir um percurso planejado e prescrito pelo professor que deve ser cumprido, controlado e avaliado por este. Busca-se atingir os objetivos previamente estabelecidos ao se encerrar o processo.

A Pedagogia Histórico-crítica se faz presente quando um dos entrevistados enfatiza a relação dialógica entre discente e docente para a efetivação do ensino e reflete a impossibilidade de programação de tempo para a aprendizagem, identificando a necessidade de desenvolvimento e amadurecimento dos sujeitos. Este percebe o homem como um ser histórico e social que se constrói nas práticas culturais vividas. Em sua fala, argumenta que:

Entrevistado 3- "Ensinar tem disso, plantar uma sementinha que vai brotar futuramente, então se acontece isso, ensinei corretamente, o aluno muitas vezes não tem maturidade para entender tudo, mas a ficha dele vai caindo aos 
poucos, quando vai fazer estágio e trabalhar, relembra o que o professor ensinou e percebe como vai usar, é inerente a formação das pessoas, são etapas, faz parte do processo de aprendizado o amadurecimento e o crescimento nosso".

Ao analisarem a relação entre ciência, cultura e tecnologia, dois entrevistados ressaltam a relevância da cultura na formação, apresentando a influência das experiências e vivências sociais dos sujeitos no processo de construção de conhecimentos, numa perspectiva de mundo do trabalho. Apenas um não faz tal consideração, ao relatar que a cultura é mais difícil de ser envolvida, o que classifica seu entendimento na perspectiva de formação para o mercado.

Ainda fundamentada na Pedagogia Histórico-critica, temos a consideração da possibilidade de formação para o desenvolvimento da criticidade por dois coordenadores. Identificam o currículo como prática cultural, capaz de captar conceitos que fundamentam a realidade nas relações que a constituem ao relatarem que:

Entrevistado 1- "Ambas as coisas, pode contribuir para o questionamento do mercado, mas é mais voltado para a técnica, o desenvolvimento crítico depende também da relação do aluno com sua história, a vivência de cada um".

Entrevistado 2- "Acho que a instituição está indo para um caminho de formar um cidadão técnico e crítico, uma vantagem de uma instituição pública como a nossa, que tem público diverso, de diversas classes e a gente como servidor público, facilita esta visão crítica de mundo para nosso aluno".

Esta questão é identificada nos documentos, no histórico da Instituição, ao pontuar a formação de cidadãos atuantes.

A fala de um coordenador, traz a pedagogia das competências; em que ressalta a necessidade de atender a demanda mercadológica, considerando o tempo de curso reduzido, devendo priorizar os conteúdos que atendam ao mercado e não a formação humana e crítica destes sujeitos. Segundo ele:

Entrevistado 3- "Formam para atender o mercado de trabalho, tem pontos que são necessários de se trabalhar, mas não se faz quatro semestres, falta em virtude da carga horária".

Cabe destacar que o desenvolvimento de competências é citado também no decorrer dos Projetos Pedagógicos de Curso conforme já mencionado anteriormente.

\section{ESTRUTURAÇÃO CURRICULAR DOS CURSOS}


Para diferenciar as concepções de formação para o mercado e para o mundo do trabalho na estruturação curricular dos cursos, considerou-se que na primeira há primazia de conteúdos técnicos, ignorando a relevância da formação humana nos sujeitos. Além disso, esta prioriza a prática, uma vez que o mercado visa trabalhadores capazes de executar o trabalho, sem a necessidade de compreender o mesmo. Já a formação para o mundo do trabalho leva em conta os apontamentos de Zatti (2016, p.1472) segundo o qual "há elementos ligados à formação humana, à formação do cidadão que são necessários independente da área técnica na qual o sujeito vai atuar". Se baseia também nas reflexões de Araújo e Rodrigues (2010, p.59) ao apresentarem que quando Marx "ressalta a necessidade de aulas teóricas e práticas nas escolas técnicas, fica-nos a indicação da necessidade de os alunos desenvolverem o hábito do manejo das ferramentas (a técnica), junto com a aquisição do conhecimento dos fundamentos dessas técnicas (a ciência)". Assim, não se restringiria à formação para uma ação prática no mercado, mas a compreensão do conhecimento científico, tão necessária uma vez que a prática se modifica permanentemente com o desenvolvimento da tecnologia.

Percebeu-se nos documentos grande valorização da formação teórica na estrutura curricular), uma vez que dos cinco PPC's investigados, quatro apresentam carga horária superior a $60 \%$ da carga horária total do curso destinada a teoria, conforme se observa na tabela 1:

Tabela 1- Carga horária das atividades desenvolvidas nos cursos

\begin{tabular}{|c|c|c|c|r|}
\hline & Teoria & \multicolumn{2}{|c|}{ Prática } & Carga \\
\hline Cursos & Aulas teóricas & $\begin{array}{c}\text { Aulas em } \\
\text { laboratório }\end{array}$ & $\begin{array}{c}\text { Prática } \\
\text { profissional }\end{array}$ & $\begin{array}{c}\text { Carional } \\
\text { horária total }\end{array}$ \\
\hline PPC 1 & $1116 \mathrm{~h} 40 \mathrm{~min}$ & $133 \mathrm{~h} 20 \mathrm{~min}$ & $180 \mathrm{~h}$ & $1430 \mathrm{~h}$ \\
\hline PPC 2 & $1050 \mathrm{~h}$ & $150 \mathrm{~h}$ & $180 \mathrm{~h}$ & $1380 \mathrm{~h}$ \\
\hline PPC 3 & $740 \mathrm{~h}$ & $300 \mathrm{~h}$ & $160 \mathrm{~h}$ & $1200 \mathrm{~h}$ \\
\hline PPC 4 & $650 \mathrm{~h}$ & $716 \mathrm{~h} 40 \mathrm{~min}$ & $180 \mathrm{~h}$ & $1547 \mathrm{~h}$ \\
\hline PPC 5 & $983 \mathrm{~h} 20 \mathrm{~min}$ & $216 \mathrm{~h} 40 \mathrm{~min}$ & $180 \mathrm{~h}$ & $1380 \mathrm{~h}$ \\
\hline
\end{tabular}

Fonte: Elaborado pela autora

As aulas teóricas fornecem um embasamento científico que possibilita a compreensão dos conhecimentos que fundamentam a prática, para que esta aconteça de forma reflexiva. Neste sentido, a distribuição da carga horária nos cursos se enquadra dentro da concepção de formação para o mundo do trabalho. A importância destes conhecimentos teóricos também é 
enfatizada na fala dos coordenadores quando são indagados sobre a importância dos conhecimentos teóricos respondem que:

Entrevistado 1- "Os conhecimentos teóricos são de grande importância. É fundamental a articulação entre teoria e prática. Acredito que o curso é de excelência, dando base de conhecimentos para os alunos buscarem soluções para resolver as questões que surgem no trabalho e se adequarem as mudanças, compreendendo o que fazem, pois tem acesso ao conhecimento científico".

Entrevistado 2- "Muito importante. Mas no curso técnico temos que ser mais pragmáticos. Nossa escola não é profissionalizante, não é um curso para botar robôs para trabalhar. A gente forma um técnico para entender o que está fazendo, o que se faz e porquê. Não é profissionalizante como o SENAI por exemplo, é técnico.

Entrevistado 3- "A grande diferença do Instituto para o Sistema S é a bagagem teórica. Consegue fazer o aluno pensar de forma real. Quando chega na indústria a parte prática é fácil de assimilar. A teoria traz vantagens”.

Consideram a base teórica como fundamental para o trabalhador compreender sua atuação prática, não apenas executar, mas ter acesso ao conhecimento científico para ter consciência do que faz. Um dos coordenadores apenas, considera que há um excesso de teoria no curso atualmente e acredita na necessidade de adaptação de conteúdos para uma forma mais prática, em laboratório, acrescentando em sua fala que:

Entrevistado 2- "o aluno tem que colocar a mão na massa também, estamos fazendo a revisão dos conteúdos e concluindo que não tem que aprofundar demais na parte teórica; que pode tentar diminuir um pouco o conteúdo teórico e tentar ensinar de uma forma mais prática no laboratório".

Dois coordenadores fazem a diferenciação entre os cursos técnicos e profissionalizantes, comparando-os a partir da bagagem teórica existente entre eles; inferindo que os primeiros formam trabalhadores capazes de pensar e compreender as atividades que executam, enquanto nos outros se faz um treinamento para execução.

A relevância dos conhecimentos teóricos na formação profissional é ressaltada por Araújo e Rodrigues (2010), que citam a proposta de Marx para a educação. Esta associa trabalho intelectual e manual, superando a dualidade de formação para o pensar ou executar. Apontam a linha de pensamento de Saviani que se identifica com Marx:

Saviani (2007) também advoga a integração entre as capacidades de pensar e de produzir como imprescindível para se instaurar uma lógica educativa interessante aos trabalhadores. Essa seria uma estratégia de enfrentamento da dualidade educacional brasileira, segundo a qual de um lado tem-se uma educação voltada para o saber-fazer, destinada aos trabalhadores, e de outro 
lado uma educação voltada para o saber-pensar, destinada às elites econômicas e políticas. De um modo geral, essa dualidade corresponde à divisão técnica do trabalho que aparta os trabalhadores de funções operativas dos demais com funções de concepção e gerência dos processos (ARAÚJO E RODRIGUES, 2010, P. 59).

Analisando os componentes curriculares, não se localizou nos projetos de cursos, disciplina específica que apontasse para o mundo do trabalho, no que diz respeito à formação política e humana dos trabalhadores, para refletirem o sentido ontológico e histórico/social do trabalho. Observa-se nas ementas das disciplinas, que a estrutura curricular se constitui a partir de conhecimentos técnicos, numa concepção de formação para o mercado. Em três documentos encontra-se a disciplina Ciências ambientais aplicadas, que indica uma reflexão social do trabalho para além da economia uma vez que demonstra preocupação com problemas ambientais e o consumismo. No discurso dos coordenadores é revelada também a inexistência de disciplinas com conteúdos voltados exclusivamente para a formação humana, mas relatam que no contexto da prática pedagógica, surgem oportunidades de trabalhar tal formação:

Entrevistado 1- "Não tem disciplina específica, mas de forma geral, estas questões são discutidas nas aulas, entre professor e aluno".

Entrevistado 2- "Hoje não tem uma disciplina, com conteúdo específico para tratar. Não vejo. Acho que tem conteúdo extraoficial, que é um pouco da vivência do corpo docente por exemplo".

Apenas um deles relata que os conteúdos são trabalhados em duas disciplinas da área de gestão, em tópicos dizendo que:

Entrevistado 1- "hoje tem duas disciplinas na área de gestão, é tratado em tópicos, mas não diretamente".

Todos os entrevistados reconhecem a importância da inclusão de disciplinas de formação humana nos currículos, fazendo as afirmações:

Entrevistado 1- "Acredito que há espaço para a formação humana e com certeza são de grande importância, mas atualmente está complicado com a política de redução de carga horária. Temos que diminuir a carga horária de disciplinas e muitas vezes não dá pra ser apenas uma aula na semana".

Entrevistado 2- "Acho realmente. Não sei como faria, mas é uma ideia interessante, uma coisa que poderíamos buscar. Não sei se no âmbito de nossa instituição tem como fazer isso".

Entrevistado 3- "Sim, teria. Mas a dificuldade é trabalhar com o humano. A proposta no colegiado se complica. É de extrema importância, até para pensar de forma diferente a vida, a questão da redução de jornada de trabalho. Mas 
no coletivo é muito difícil fazer modificações, a interpretação dos professores gera desconforto e acaba sendo deixado de lado".

Nota-se que valorizam a formação humana na profissionalização e relatam as dificuldades encontradas para efetivar uma proposta que contemple a mesma em virtude da carga horária e da falta da conscientização coletiva; neste sentido, possuem concepções de formação para o mundo do trabalho.

\section{CONSIDERAÇÕES FINAIS}

Considerando as categorias discutidas no presente artigo, podemos afirmar que os currículos dos cursos técnicos subsequentes/ concomitantes do IFSUDESTE-MG/campus Juiz de fora possuem concepções de Educação Profissional voltadas tanto para o mercado como para o mundo do trabalho, indicando que as mesmas podem caminhar juntas. Nos documentos há elementos que trazem a preocupação com o papel social da educação, além do caráter econômico e nos discursos dos entrevistados existe conscientização da importância da formação humana dos trabalhadores.

Destaca-se na concepção de formação para o mercado de trabalho a consideração do trabalho enquanto atividade remunerada, associada ao emprego, em que o caráter ontológico do trabalho é desconsiderado, nas duas fontes de dados analisadas. Assim, o trabalho assume o sentido histórico no contexto capitalista, onde o trabalhador é preparado para atender a demanda do sistema produtivo, sendo a formação profissional embasada em teorias não críticas e críticas de currículos com Pedagogias das Competências e Tecnicista.

Na perspectiva de mundo do trabalho é relevante a consideração do desenvolvimento humano e social dos discente na Educação Profissional, sendo superada a visão restrita de formação técnica do trabalhador. Esta forma de oferta do ensino técnico é concebida como ampliadora da visão crítica dos discentes e aborda-se a relevância da formação humana, enfatizando uma formação mais abrangente, para a vida e não apenas para o emprego. Neste caso aparece uma perspectiva pós-crítica de currículo, identificando o mesmo como prática cultural, embasada na Pedagogia Histórico-crítica.

Pelo sólido embasamento teórico, os cursos possibilitam a formação de sujeitos que compreendam as atividades realizadas e possam criar, não sendo meros executores; desta forma se diferenciam de cursos profissionalizantes. Entretanto, percebeu-se que a formação para o mundo do trabalho, com a inclusão de disciplinas de formação humana, é dificultada pela carga 
horária dos cursos. Apesar dos coordenadores de cursos reconhecerem a relevância destas disciplinas, há uma limitação de tempo que acaba fazendo que outros conteúdos sejam priorizados; ficando estes submissos ao contexto da prática pedagógica, em que os professores abordam informalmente questões sociais e políticas que podem ter caráter humanizador. Outra questão importante é a conscientização do coletivo de professores acerca do papel emancipador da Educação Profissional, uma vez que a construção dos projetos pedagógicos de curso se faz pelos mesmos e para se pensar um currículo que abarque a formação para o mundo do trabalho é preciso que os sujeitos envolvidos tenham conhecimentos a respeito para estudarem adequações no tempo de forma a incluir os conteúdos que sejam de fato valorizados por eles.

Conclui-se assim que os cursos técnicos subsequentes/concomitantes são cursos de curta duração, com enfoque principal na formação de trabalhadores para inserção no mercado de trabalho, mas não se omitem também da formação para o mundo do trabalho ao promoverem a criticidade dos educandos com uma formação técnica que permite pensar o conhecimento científico e não apenas executar atividades no mercado. Neste sentido, formam indivíduos com autonomia de pensar o trabalho. Confirma-se a possibilidade de criação de currículos voltados para a transformação social nesta modalidade de ensino, que articule formação para o mercado com a Educação Emancipatória dos sujeitos, preocupados com a formação humana além da técnica. Para tanto, é necessária a prática reflexiva dos educadores sobre a Educação Profissional e seu papel não apenas econômico, mas também social o que se faz através da formação continuada, que deve ser incentivada pela Instituição.

Cabe ainda destacar que esta pesquisa limitou o estudo dos currículos aos discursos dos coordenadores de cursos e dos Projetos Pedagógicos dos mesmos. Foram eleitos como objeto por serem consideradas de grande importância na constituição dos mesmos. Entretanto, o currículo tem um caráter bem mais amplo, diz respeito a toda cultura escolar, incluindo também as relações interpessoais, a organização do espaço e os demais documentos que orientam as ações. Além disso, os discursos dos entrevistados representam a experiência individual de cada um e estes foram escolhidos como participantes pela importância de suas atuações na construção dos currículos, mas não se pode generalizar, afirmando que tais concepções são compartilhadas pelo coletivo de professores, o que demanda nova pesquisa.

\section{REFERENCIAS}


ARAÚJO, Ronaldo Marcos de Lima; RODRIGUES, Doriedson do Socorro. Referências sobre práticas formativas em educação profissional: o velho travestido de novo frente ao efetivamente novo. Revista B. Téc. Senac: a R. Educ. Prof., Rio de Janeiro, v. 36, n. 2, p. 51-63, maio/ago. 2010. Disponível em: https://www.bts.senac.br/bts/article/view/218/201. Acesso em: 23 de setembro de 2020.

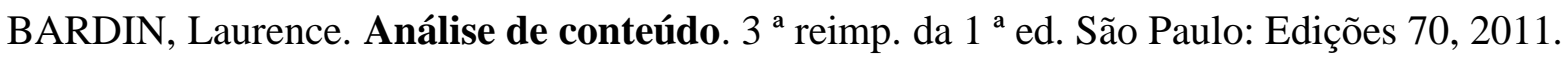

CIAVATTA, Maria; RAMOS, Marise. Ensino Médio e Educação Profissional no Brasil: Dualidade e fragmentação. Brasília. Revista Retratos da Escola, v. 5, n. 8, p. 27-41, jan. /jun. 2011. Disponível em: http//www.esforce.org.br. Acesso em: 20 de agosto de 2020.

DANTE, Henrique Moura. Trabalho e formação docente na educação profisssional. $1^{\mathrm{a}}$ ed. Curitiba: IFPR-EAD. Coleção formação pedagógica. V. III, 2014.

FUNDAÇÃO OSWALDO CRUZ. Escola politécnica de saúde Joaquim Venâncio (Org.). Dicionário da educação profissional em saúde. Rio de Janeiro: Fundação Oswaldo Cruz, Escola Politécnica de Saúde Joaquim Venâncio, 2009. Disponível em: http://www.epsjv. fiocruz.br/sites/default/files/143.pdf. Acesso em: 23 de setembro de 2020.

FREIRE, Paulo. Pedagogia da autonomia: saberes necessários à prática educativa. $25^{\mathrm{a}}$ ed. São Paulo: Paz e Terra, 1996. (Coleção leitura).

FRIGOTTO, Gaudêncio. A produtividade da escola improdutiva. São Paulo: Cortez, 2006.

FRIGOTTO, Gaudêncio. A polissemia da categoria trabalho e a batalha das ideias nas sociedades de classe. Revista Brasileira de Educação, v. 14 n. 40 jan. /abr., p. 168-194, 2009. Disponível em: https://www.scielo.br/pdf/rbedu/v14n40/v14n40a14.pdf. Acesso em: 23 de setembro de 2020.

IFSUDESTEMG. CAMPUS JUIZ DE FORA. Projeto pedagógico do curso técnico em Eletrônica. Juiz de Fora: 2018.

IFSUDESTEMG. CAMPUS JUIZ DE FORA. CAMPUS JUIZ DE FORA. Projeto pedagógico do curso técnico em Eletrotécnica. Juiz de Fora: 2018.

IFSUDESTEMG. CAMPUS JUIZ DE FORA. Projeto pedagógico do curso técnico em Eletromecânica. Juiz de Fora: 2017.

IFSUDESTEMG. CAMPUS JUIZ DE FORA. Projeto pedagógico do curso técnico em Mecânica de nível médio concomitante/subsequente. Juiz de Fora: 2018

IFSUDESTEMG. CAMPUS JUIZ DE FORA. Projeto pedagógico do curso técnico em Metalurgia. Juiz de Fora: 2017.

MÉSZÁROS, István. A educação para além do capital. $2^{\text {a }}$ ed. São Paulo: Boitempo, 2008. 
RAMOS, Marise. O currículo na perspectiva de classe: desafios e possibilidades para a educação profissional. Cascavel. Unioeste. Educere et Educare: Revista de Educação, v. II, n.23 Jul/Dez 2016.

SAVIANI, Dermeval. O choque teórico da Politecnia. Revista Trabalho, educação e saúde, 2003, vol.1, n.1, p.131-152, 2003. Disponível em: https://www.scielo.br/pdf/tes/v1n1/10.pdf. Acesso em: 23 de setembro de 2020.

ZATTI, Vicente. Institutos Federais de Educação: um novo paradigma em educação profissional e tecnológica. Revista Ibero-Americana de Estudos em Educação, v. 11, n. 3, p.1461-1480, 2016. Disponível em: https//periódicos.fclar.unesp.br/iberoamericana/article/view/7555/5920. Acesso em: 23 de setembro de 2020. 